\title{
MERCADO E SOFRIMENTO: AS CONEXÕES DA ALIENAÇÃO DO SUJEITO NA CONTEMPORANEIDADE
}

\author{
MARKET AND SUFFERING: THE CONNECTIONS OF ALIENATION \\ OF THE SUBJECT IN THE CONTEMPORANEITY
}

\section{Daniel Chaves de Brito ${ }^{1}$ Jaime Luiz Cunha de Souza² Aucilene Moraes de Brito $^{3}$}

\footnotetext{
1 Professor Titular da Faculdade de Ciências Sociais da Universidade Federal do Pará (UFPA). E-mail: dnlbritodc02@gmail.com

2 Professor do Programa de Pós-Graduação em Segurança Pública (PPGSP) e do Programa de Pós-Graduação em Ciência Política (PPGCP), da Universidade Federal do Pará (UFPA). E-mail: jaimecunha@ufpa.br

3 Professora de Geografia da SEMEC-PMB e Graduando em Psicologia da Universidade da Amazônia (UNAMA). E-mail: aucilene.brito@hotmail.com
}

"Na sociedade de consumidores, ninguém pode se tornar sujeito sem primeiro virar mercadoria" (BAUMAN, 2008, p. 20).

RESUMO: O texto, especialmente, objetiva trazer uma reflexão sobre a sociedade de consumo e suas implicações, tanto para os sujeitos quanto para o processo civilizatório. O trabalho parte da tentativa de uma caracterização da modernidade com base na teoria elaborada por Karl Marx e o conceito de mercadoria; a partir de então apoiado na teoria de Sigmud Freud mostra os fatores desencadeantes do mal-estar na civilização; e, finalmente, com as contribuições de Theodor Adorno e Max Horkheimer, Anthony Giddens e Zygmunt Bauman aponta as consequências de uma época de aprofundamentos alienantes em torno da sociedade de consumo.

Palavras-Chave: Modernidade. Alienação. Sofrimento.

ABSTRACT: The text, especially, aims to bring a reflection on the consumer society and its implications, both for the subjects and for the civilizing process. The work starts from the attempt of a characterization of modernity based on the theory elaborated by Karl Marx and the concept of commodity; From then on, based on the theory of Sigmud Freud, he shows the triggering factors of malaise in civilization; and finally, with the contributions of Theodor Adorno and Max Horkheimer, Anthony Giddens and Zygmunt Bauman points to the consequences of a time of alienating deepening around consumer society.

Keywords: Modernity. Alienation. Suffering.

Sumário: Introdução - 1 A Modernidade e suas transformações - 2 O fetichismo e a face oculta da mercadoria - 3 A civilização entre Eros e o sofrimento - 4 O preço da civilização moderna - 5 A mercadoria e o fetichismo da subjetividade - Considerações Finais - Referências

\section{INTRODUÇÃO}

Nos dias atuais frequentemente nos depararmos com termos os mais diversos que tentam definir a sociedade moderna. Os profissionais das ciências humanas já lidam corriqueiramente com uma variedade deles, exemplos: sociedade em rede ou da informação (CASTELL, 2000), sociedade da aceleração (VIRILIO, 1996), sociedade do cansaço (BYUNG, 2015), sociedade da decepção (LIPOVETSKY, 2007), sociedade de consumo (BAUDRILLARD, 1995), sociedade do espetáculo (DEBORD, 2016). Todos esses títulos que à primeira vista parecem tão dispares carregam em si um elo de ligação.

Tratam das mudanças que vem ocorrendo dentro da própria modernidade e relatam sempre a perda de algo, sempre algo que já era precário e que nestes tempos deixou de existir. Perda, neste sentido, também 
pode significar um aumento dos níveis de ansiedade. A proposta deste texto é apresentar os meandros da transformação do sujeito consumidor, ele próprio, numa mercadoria. E mapear na obra de alguns autores importantes as consequências dessa transformação e as fontes do sofrimento, do mal-estar do homem moderno, do seu pathos.

O trabalho parte da tentativa de uma caracterização da modernidade buscando entender como ela se estabeleceu e quais eram as suas perspectivas; em seguida, com base na teoria elaborada por Karl Marx, procede-se uma apresentação do conceito de mercadoria e sua principais faces; a partir de então apoiado na teoria de Sigmud Freud, tenta-se entender os fatores desencadeantes do mal-estar na civilização; e, finalmente, se valendo das contribuições de Theodor Adorno e Max Horkheimer, Anthony Giddens e Zygmunt Bauman tentou-se mostrar quais as consequências trazidas por essa época de aprofundamentos alienantes em torno da mercadoria.

\section{A MODERNIDADE E SUAS TRANSFORMAÇÕES}

As principais narrativas sobre a modernidade não escondem as dificuldades de assentar um termo, que definitivamente caracterize os tempos atuais, seu zeitgaist. Assim, na chamada contemporaneidade que são os tempos atuais, uma série de propostas vão surgindo e tomando seu lugar na disputa semântica pelo poder de ser lembrada sempre que os problemas que atingem a sociedade ou indivíduo, também vão se perfilhando. Pensando nesta dificuldade Giddens (1991, p. 08) faz-se a seguinte pergunta: "O que é modernidade?".

Para este autor trata-se de um estilo, costume de vida ou organização social que apareceu na Europa a partir do século XVII e que passou a influenciar, ou mesmo, conflitar com outros estilos e costumes de vida ao redor do mundo. No entanto é interessante atentar para a conclusão estabelecida para esta questão, diz ele: "Isto associa a modernidade a um período de tempo e a uma localização geográfica inicial, mas por enquanto deixa suas características principais guardadas em segurança numa caixa preta" (GIDDENS, 1991, p. 08).

O que se percebe é que num período, de pelo menos três séculos, aquilo que se desenvolveu, ou até mesmo nasceu, na Europa vem submetendo homens e mulheres a um padrão único de estratégia de sobrevivência. A modernidade não deixa suas características a amostra, certamente porque é desde sua origem um período da história da civilização marcado pela fragmentação. Em tempos anteriores ao século XVII, o padrão de organização social podia ser caracterizado pelo forte poder da tradição, que dava sustentação a uma ordem social estamental, fixada numa rígida estrutura hierárquica que definia o lugar de cada grupo social (uma sociedade do controle social).

A modernidade representa nada mais nada menos que a ruptura com essa ordem. A sua perspectiva é a de estabelecer uma ordem social, em que a igualdade seja o princípio fundamental (uma sociedade do autocontrole $)^{1}$. E é, certamente, neste âmbito que reside os principais problemas de se caracterizar e sobretudo de encontrar os princípios fundamentais da modernidade. A dificuldade se estabelece e se aprofunda à medida em que os grupos sociais são deixados para trás e vai se firmando a figura do indivíduo. Mas foi o direito, também moderno, que assentou as bases jurídicas do individualismo e determinou a existência de uma sociedade, que deveria despertar todas as forças econômicas e políticas dentro de um ordenamento legal onde cada um deveria lutar em busca de seu lugar, orientado por um princípio de racionalidade objetiva (WEBER, 1991).

Se a tradição estabeleceu seus fundamentos no passado, a modernidade os assenta no presente ou até mesmo no futuro. A ideologia do progresso é a força que orienta o destino de cada um. Assim, "novos processos, sobretudo econômicos e políticos, surgem e rumam em um ritmo extraordinário para o futuro. A noção de futuro quase perde o que ela representa, pois nestes tempos o moderno é futuro realizado ou

${ }^{1}$ Elias (1993) faz uma reflexão da modernidade destacando que esta se caracteriza por ter estabelecido uma ordem social que superou o controle social e se transformou numa sociedade do autocontrole (ver sobretudo vol II, parte II). 
realizável em breve" (BRITO \& BARP, 2008, p. 23). Balizados pela ideia de progresso e de futuro, a modernidade, no percorrer de três séculos, mergulhou a humanidade na "era das incertezas".

Não é, a partir desta análise, necessário grandes esforços analíticos para deduzir que a modernidade nada mais é do que as balizas de um sistema econômico e político que liberou o mundo ocidental das amarras da tradição e o direcionou aos limites da incerteza. Hoje já está bastante claro que o capitalismo moderno e o Estado moderno não garantem em absoluto nem uma vida econômica satisfatória e nem a sobrevivência de uma vida segura. Por isso vale atentar pra esta afirmação: "esperar que o Estado, se chamado ou pressionado adequadamente, fará algo palpável para mitigar a insegurança da existência não é muito mais realista do que esperar o fim da seca por meio de uma dança da chuva" (BAUMAN, 2003, p. 102).

Mas, de modo algum esta é uma situação recente. Quando se observa a linha do tempo, verifica-se que passadas as euforias do movimento iluminista vem à tona as primeiras reflexões que apresentam um diagnóstico da modernidade apontando uma série de dificuldades e propondo uma correção de percurso.

\section{O FETICHISMO E A FACE OCULTA DA MERCADORIA}

Entre as várias tentativas de entender a modernidade, provavelmente nenhuma reflexão foi tão longe quanto aquela levada a efeito por Marx (1818-1883). Ao assentar as diretrizes de um futuro partido, para viabilizar politicamente os interesses dos trabalhadores assalariados, Marx fez um profundo diagnóstico dos desdobramentos históricos da formação do capitalismo destacando suas patologias juntamente com as da sociedade industrial. Na obra, o Manifesto do Partido Comunista, o objetivo era determinar uma perspectiva de futuro, apontando para a necessidade de uma extraordinária mudança social, da qual os trabalhadores seriam os protagonistas.

Nessa análise ele ressalta positivamente o papel histórico da classe burguesa, que tinha se tornado o ator principal da ruptura com o passado. Assim, diz ele: "a burguesia desempenhou na história um papel revolucionário decisivo". Para ele a burguesia tinha sido responsável pela liberação das forças produtivas, pela ciência moderna (apoiada nos fundamentos de uma razão laica) e por colocar em marcha o progresso. Porém, não é difícil perceber que a análise desenvolvida por este autor está envolta em uma retórica da qual o leitor não escapa de ser envolvido na dramática destruição da velha sociedade baseada num rígido status quo.

A sociedade moderna se erigiu sobre os escombros das relações sociais feudais, relações sociais orientadas pelo direito e pelo cálculo racional dos investimentos econômicos e assim se reporta o autor: "onde quer tenha chagado ao poder a burguesia destruiu todas as relações feudais[...], e não deixou subsistir entre os homens outro laço senão o interesse nu e cru, senão o frio dinheiro vivo" (MARX E ENGELS, 2001, p. 27). Para este autor, as mudanças postas em marcha, nenhuma delas era mais traumática para a civilização do que a quebra dos valores da dignidade humana. Para ele o capital foi a força que reduziu todas as relações pessoais a um simples valor de troca e todas as liberdades, a liberdade comercial e conclui que

A burguesia despojou de sua aura todas as atividades até então consideradas com respeito ao temor religioso. Transformou o médico, o jurista, o padre, o poeta, o homem de ciência, em assalariados remunerados... A burguesia rasgou o véu de emoções e de sentimentalidade das relações familiares e reduziuas a mera relação monetária (MARX E ENGELS, 2001, p. 28).

Ao se observar estas reflexões, em que o autor diz que o capital reduziu as relações humanas à subserviência do cálculo econômico, em que a lógica da valorização do valor, a lógica do lucro, torna-se o fundamento das relações sociais, é possível perceber que Marx aponta para os fundamentos daquilo que ele denomina, em sua análise da economia política, de reprodução do capital. Essa análise, que aparece com toda a sua força em O Capital: Uma Crítica da Economia Política, parte de uma categoria central que representa o ícone mais emblemático do capitalismo moderno, trata-se da mercadoria.

Nunca é demais estabelecer que a maior contribuição das análises levada a efeito por Marx e que de 
certa forma tornou exposta as entranhas do modo de produção capitalista, deu-se a medida em que ele põe a luz os segredos da mercadoria. A maior transformação operada pelo capitalismo, onde quer que ele tenha florescido, foi o poder de transformar produtos produzidos pelos homens em mercadoria e submeter a satisfação das necessidades a aquisição delas num sistema de mercado. A mercadoria, como afirma o autor, é coisa trivial, mostra-se por meio de seu valor de uso, como a satisfação de uma necessidade humana.

Mas quando se analisa mais de perto "vê-se que ela é algo muito estranho, cheia de sutilezas metafísicas e argúcias teleológicas” (MARX, 1988, p. 79). E prosseguindo afirma: “A mercadoria é misteriosa simplesmente por encobrir as características sociais do próprio trabalho do homem”. (MARX, 1988, p. 81). Assim, para Marx o trabalho histórico do capital, ao reduzir tudo na sociedade capitalista ao cálculo econômico, foi criar uma visão de mundo com mecanismos eficazes que impedisse a sociedade de manter contato com a realidade do mundo da produção de mercadorias. Ao assentar sobre a mercadoria, por meio do valor de uso, o valor de troca, o capitalismo embasou sua reprodução na constituição de um trabalho alienado, em um mundo dominado pelo fetichismo da mercadoria e pela reificação das relações sociais.

Dentre as principais propostas desta análise, vale não perder de vista de que forma o ser humano, ao aparecer no mercado de trabalho - como mão de obra - se transformaria em uma mercadoria incorporando todas as suas sutilezas. Acredita-se que por meio das noções de alienação, fetichismo e reificação seria possível traçar um diagnóstico da sociedade capitalista e trazer à luz sua verdadeira natureza. Pois de uma maneira bem específica, compreender o universo da modernidade, os meandros da reprodução do capital, sob os princípios da ciência racional, seria possível traçar uma alternativa que levasse a civilização ao seu verdadeiro destino, tornar-se sujeito de sua história em busca da felicidade.

\section{A CIVILIZAÇÃO ENTRE EROS E O SOFRIMENTO}

Não é difícil admitir que a contribuição científica levado a efeito por Marx, permitiu aprofundar a compreensão da dramaticidade que a modernidade e seu sistema econômico haviam submetido o processo civilizatório. Mas não se pode fechar os olhos para outras contribuições igualmente importantes, como as de Sigmund Freud, para a compreensão do drama da modernidade. Da vasta obra de Freud, a que aborda com mais profundidade o problema que se está refletindo, é Mal-Estar na Civilização. Embora este seja um trabalho complexo, com uma tese robusta e bem fundamentada, sobre o antagonismo intransponível entre as exigências da pulsão e as da civilização, ela tem por objetivo não mostrar os caminhos que levariam a felicidade, mas o porquê de a felicidade não necessariamente está disponível para o homem e sua civilização.

Nesse passo a questão principal seria entender como os homens percebem a finalidade e a intenção da vida, diz Freud (2010, p. 29) “O que pedem eles (os homens) da vida e desejam nela alcançar?” E prosseguindo diz: "é difícil não acertar a resposta: eles buscam a felicidade, querem se tornar e permanecer felizes”. Mas, a rigor não é esta questão que preocupa este autor, o que está em jogo é entender exatamente isto: "a vida tal como nos coube, é muito difícil para nós, traz demasiadas dores, decepções, tarefas insolúveis" (FREUD, 2010, p.28).

Para Freud, as fontes do sofrimento podem ser distinguidas na prepotência da natureza, na fragilidade do corpo humano e na insuficiência das normas que regulam os vínculos humanos na família, no Estado e na sociedade (FREUD, 2010, p. 43). Seguindo um caminho bem peculiar, o autor vai pontuando a sua discordância quanto ao que chamou de hostilidade a civilização, à medida que esta, também, não responderia aos anseios da felicidade do homem.

Para este autor não seria o abandono desta em prol de uma vida simples, também não é soltando as amarras da civilização livrando o homem das neuroses provocadas pelas medidas de privação impostas em nome da cultura, nem o progresso da ciência, que levou o homem a submeter as forças da natureza, que seriam capazes de levar ao alcance da felicidade. Assim, tão somente a "civilização designa a inteira soma das realizações e instituições que afastam a nossa vida daquela de nossos antepassados animais". E seus objetivos seriam apenas "a proteção do homem contra a natureza e a regulamentação dos vínculos dos homens entre si” (FREUD, 2010, 49). 
Assim, a civilização em sua caminhada tem de enfrentar o poderoso obstáculo que representa o instinto de agressividade do ser humano. Neste processo a cultura representa, a serviço de Eros, a tentativa de reunir a humanidade em torno de uma unidade social, a comunidade, enquanto o "instinto natural de agressão dos seres humanos, a hostilidade de todos contra todos e de todos contra um" (FREUD, 2010, p. 91), representa o instinto de morte. Com isso o sentido da evolução cultural está representado nesta luta entre "Eros e morte, instinto de vida e de destruição, tal como se desenrola na espécie humana" (FREUD, 2010, p. 91).

E conclui o autor; “essa luta é o conteúdo essencial da vida, e por isso a evolução cultural pode ser designada, brevemente, como a luta vital da espécie humana” (FREUD, 2010, p. 91). Mas provavelmente toda a síntese dessa análise pode ser percebida nessa breve reflexão; “A civilização controla então o perigoso prazer em agredir que tem o individuo, ao enfraquecê-lo, desarmá-lo e ao fazer com que seja vigiado por uma instância em seu interior, como uma guarnição numa cidade conquistada" (FREUD, 2010, p. 92). O que Freud traz à compreensão é que a civilização, desenvolve-se com o homem tendo que sublimar a satisfação pusional.

Nesta luta entre Eros e pulsão de morte, o preço que a civilização tem a pagar é ter que carregar o fardo do sentimento de culpa e este é para o autor o problema mais importante da evolução da cultura. Em suas palavras "o preço do progresso cultural é a perda da felicidade, pelo acréscimo do sentimento de culpa" (FREUD, 2010, p. 106). É sem dúvida neste contexto que se situa o mal-estar da civilização que as instituições, as quais são produto da engenhosidade humana, como a religião, tentam redimir a humanidade desse pecado. A partir disto o autor não passa sem lembrar que o ponto mais importante para a civilização é saber se a evolução cultural poderá instituir meios que possam controlar efetivamente os instintos de agressão e autodestruição que podem por em perigo a existência do homem. Nesse contexto vale apena escutar o que tem Freud para dizer.

Atualmente os seres humanos atingiram um tal controle das forças da natureza, que não lhes é difícil recorrer a elas para se exterminarem até o último homem. Eles sabem disso; dai em boa parte o seu desassossego, sua infelicidade, seu medo. Cabe agora esperar que a outra das duas 'potências celestiais', o eterno Eros, empreenda um esforço para firmar-se contra o adversário igualmente imortal. Mas quem pode prever o sucesso e o desenlace? (FREUD, 2010, p. 122).

Tendo por base essa reflexão, num texto divulgado pelo menos dez anos antes do começo da segunda guerra mundial, não é difícil imaginar o horizonte de conflitos que se colocava diante de Freud. É provável que o autor ao proferir as palavras acima estivesse percebendo um enfraquecimento de Eros e não tardou para que a orgia da pulsão de morte tomasse conta do mundo. Neste âmbito o século XX trouxe à tona as forças destrutivas mais poderosas que a humanidade ate então se defrontou. Parece que os elementos de sublimação dos instintos por um instante perderam a eficácia, e a violência passou a dar as cartas na ordem da civilização ocidental.

\section{O PREÇO DA CIVILIZAÇÃO MODERNA}

O que se tem até aqui não é de modo algum, pouca coisa, o quadro traçado por Marx e Freud, expondo as entranhas da civilização moderna e evidencia claramente as dificuldades para a civilização avançar. Não é um projeto simples superar a alienação social, a redução do ser humano a reificação econômica e remover o fetichismo da visão de mundo; assim como assentar instrumentos de controle culturais que pudessem ao mesmo tempo direcionar e eliminar o sofrimento, a infelicidade, provocado pela pulsão de morte. Diante desse quadro Adorno e Horkheimer (membros da conhecida Escola de Frankfurt), em sua mais representativa obra Dialética do Esclarecimento, apresentam um diagnóstico da modernidade, apontando os meandros pelos quais a civilização moderna deixou pairar sobre si as forças da pulsão destrutiva.

Os autores, tanto leitores de Marx quanto de Freud e que não escondem sua admiração por ambos, 
analisaram o fracasso do iluminismo. Depois de olharem para a história da modernidade, e sobretudo para a ciência e a técnica modernas, e compararem com o chamado projeto do iluminismo (que segundo Kant ${ }^{2}$, tiraria o homem da menoridade, e este seria emancipado das forças mitológicas apoiados em conhecimentos racionais, levando ao desencantamento do mundo) declaram, as luzes do iluminismo ofuscaram a visão do homem moderno. Uma rápida olhada na teoria marxista pode-se vislumbrar que o socialismo científico era o desdobramento positivo do iluminismo.

A revolução burguesa, de que falou Marx, era a condição necessária para pôr em marcha o socialismo e a emancipação do homem das forças que mantinham a dominação sobre ele. Este autor acreditou que a dominação burguesa sobre os meios de produção (a base econômica) e sobre os instrumentos ideológicos (superestrutura), uma vez rompidas tirariam a humanidade do estado de ignorância e o homem seria senhor num mundo desencantado. Freud também viu de forma bastante positiva o domínio do homem sobre a natureza e olhando para o futuro não teve dúvida em vislumbrar que: "épocas futuras trarão novos, inimagináveis progressos nesse âmbito da cultura, aumentarão mais ainda a semelhança com Deus" (FREUD, 2010, p. 52).

No entanto, os acontecimentos do século XX parecem ter demonstrado que o projeto do iluminismo tinha apenas aumentado exponencialmente os sofrimentos do homem. Horkheimer e Adorno foram profundamente atrás de desvendar a fórmula "saber é poder" e nesse passo vão trazer à tona as contradições em que o esclarecimento se envolveu. E afirmam: "o mito converteu-se em esclarecimento e a natureza em mera objetividade. O preço que os homens pagam pelo aumento de seu poder é a alienação daquilo sobre o que exercem o poder" (ADORNO \& HORKHEIMER, 1985, p. 24).

Assim, no momento em que entra em cena o iluminismo, observamos também o domínio da ofuscação; onde surgiu o avanço das ideias de progresso, logo se observa a regressão da visão de mundo; e onde levantou-se a civilização, também se manifestou a barbárie. Para Horkheimer e Adorno o resultado do desencantamento científico do mundo foi ter levado a técnica moderna e seu corolário o capitalismo industrial e financeiro, a posição de senhor do mundo.

E com isso desvendaram um mito, o iluminismo, ele próprio e suas ideia de liberdade e emancipação do homem das forças da natureza, não passaram de um mito. Como se viu, Marx acreditou que alienação era o exercício de poder de uma classe sobre outra, mas o que descobriram os autores da dialética do esclarecimento, foi que alienação insidia sobre a compreensão de todos, e com isso estava de pé a sociedade de massa.

Sabe-se que apenas existem pontos coincidentes entre as ideias de Marx, Freud e Adorno e Horkheimer (e certamente de muitos outros autores), mas a importância dessas reflexões é que, de um modo ou de outro, elas apresentaram os desdobramentos históricos da sociedade moderna. E por meio dessas análises que se percebe na sociedade de massa, as coisas não estão no mundo para atender as necessidades dos homens, mas os homens estão no mundo para atender as "necessidades" das coisas.

Provavelmente, esta inversão tem um custo psicológico demasiado grande para os homens e mulheres desta contemporaneidade. Ao se debruçarem sobre os problemas sociais da atualidade autores como Giddens e Bauman, aprofundaram esse quadro e mostram os limites das possibilidades de uma retomada de um processo em que o homem novamente seja o sujeito de um projeto de emancipação. Giddens, parte da ideia de que se pode caracterizar estes tempos como de uma modernidade reflexiva, nela se vive dentro de uma ambiguidade em que os temas são: segurança versos perigo e confiança versos riscos (GIDDENS, 1991, p. 16).

Nesse âmbito as instituições da modernidade não estão voltadas para proteger os homens, mas para assegurar que os mercados desfrutem da confiança em seu funcionamento. Na modernidade reflexiva somos obrigados a confiar, no que o autor designa como sistemas peritos, mesmo que desconhecendo completamente como eles se estabelecem, eles têm, na sociedade de massa, o papel de dar a última palavra sobre o controle dos riscos e dos perigos.

${ }^{2}$ Ver O Que é Esclarecimento? (1985). 


\section{A MERCADORIA E O FETICHISMO DA SUBJETIVIDADE}

Mas provavelmente, quem melhor descreveu e analisou os meandros desta era de uma civilização movida pela ambivalência, tenha sido Bauman. Já em uma de suas primeiras obras (Modernidade e Ambivalência), o autor admite que o termo ambivalência se presta bem para caracterizar a modernidade, porque somente ele pode definir um momento de ansiedade em que o ser humano é incapazes de ler adequadamente a situação e optar entre ações alternativas, pois ambivalência indica desordem (BAUMAN, 2003, p. 09).

Assim, tendo como pano de fundo da modernidade a ambivalência, a análise de Bauman, chega até ao Mal-Estar da Pós Modernidade. Nesta obra, ele também, apresenta o seu diagnóstico da sociedade contemporânea e afirma: "os prazeres da vida civilizada, e Freud insiste nisso, vem num pacote fechado com os sofrimentos, a satisfação com mal-estar, a submissão com rebelião” (BAUMAN, 2003, p. 08). Daqui em diante, esse autor, reconhece uma profunda mudança dentro da própria modernidade. Ele admite a existência de algo muito diferente das estruturas sociais, políticas e culturais que definiram, o que denominou modernidade sólida.

Desse modo a pós-modernidade se caracteriza pela fluidez, a imagem com a qual ele trabalha é que "os fluidos não fixam o espaço e nem prendem o tempo [...] Os fluidos não se atêm muito a qualquer forma e estão constantemente prontos (e propensos) a mudá-la. Assim, para eles o que conta é o tempo, mais do que o espaço que lhes toca ocupar" (BAUMAN, 2003, p. 8).

Entender a modernidade líquida passa a ser o grande tema sociológico por trás de todos os trabalhos posteriores de Bauman ${ }^{3}$. E é dentro dessa chave analítica, que ele vai apresentar uma reflexão sobre a mercadoria. Em seu ensaio Vidas para Consumo: A Transformação das Pessoas em Mercadorias, considera que a principal transformação social acontece no momento em que a modernidade sólida, que deu vida a uma sociedade de produtores de mercadorias, que como Marx já havia percebido ultrapassava os limites dos bens meramente materiais, transforma-se numa modernidade líquida trazendo ao mundo uma sociedade de consumidores.

Nesse âmbito, especificamente, a preocupação é entender o funcionamento de um mercado de trabalho em que a mercadoria é o próprio homem. Pode-se resumir tudo isso na seguinte pergunta: que tipo de pessoas são demandadas por esse mercado? Nesta fase as pessoas são levadas a mobilizar uma série de recursos para aumentar o seu valor no mercado, pois ela precisa tornar-se um produto atraente e desejável. Nesse processo, elas são produtores das mercadorias e as mercadorias que promovem e, assim diz o autor: "são simultaneamente, o produto e seus agentes de marketing, os bens e seus vendedores" (BAUMAN, 2008, p.13). E mais adiante conclui: "numa sociedade de consumidores tornar-se uma mercadoria desejada e desejável é a matéria de que são feitos os sonhos e contos de fadas” Baumam, 2008, p. 22).

Aqui já se percebe aquilo que Marx determinou como a chave para o entendimento da mercadoria no sistema capitalista. Assim, se está diante do fetichismo. Sabendo-se que a compreensão do fetichismo da mercadoria leva a entender que elas vieram pra assumir o lugar de sujeito no sistema social. E esse foi para Marx um processo tão extraordinário, "um fenômeno mais fantástico do que se (a mercadoria) dançasse por iniciativa própria” (MARX, 1988, p. 80). O objetivo aqui seria ocultar das vistas a substância humana da sociedade de produtores, já na sociedade de consumidores o fetichismo se volta para a subjetividade, seu foco é ocultar a realidade demasiada comodificada ${ }^{4}$. Está claro que o fetichismo da subjetividade é um embuste, um ardil que tenta fixar uma pseudo soberania do consumidor.

Mas a regra é: no mundo das mercadorias, aquelas que não cumpre as expectativas, o seu destino é

\footnotetext{
3 Além da obra Modernidade Líquida (2001), publicou também, Amor Líquido (2004); Vida Líquida (2007a); Tempos Líquidos (2007b) Medo Líquido (2008).

4 "Comodificação refere-se ao fenômeno contemporâneo em que muitos bens, serviços, ideias e também pessoas - outrora considerados não comerciais - passam a ser transformados em mercadorias vendáveis. Na comodificação, "tudo passa a ter um preço", representando a centralidade que o consumo - em detrimento da produção - ocupa na vida cotidiana” (GREHS BECK \& HERMINIO CUNHA, 2017, p. 137).
} 
o lixo, o descarte, "a sociedade de consumidores desvaloriza a durabilidade” (BAUMAM, 2008, 31). E isso pode ser observado a partir dos próprios seres humanos. Baumam, ao se reportar a isto toma como exemplo a política de migração de alguns países, com democracias tradicionais, e diz que estes praticam a "migração seletiva", e conclui com uma frase do então ex-ministro do interior, Nicolas Sarkosy em que afirma: a França deve ser capaz de escolher seus migrantes segundo suas necessidades (BAUMAN, 2008, p. 12). Mas, o que resta a fazer com os que não são recebidos e acolhidos, os que não atendem as necessidades? Será que são entregues a uma das muitas empresas da indústria da reciclagem?

Ao ponto em que chega essa reflexão, não é difícil voltar-se mais uma vez as precursoras lições de Freud. A civilização, dizia ele aquela altura, tem um preço. No estado natural a liberdade é incomensurável, mas a insegurança também, sob o domínio da civilização, submetido a um conjunto de normas legais e morais, limitando as liberdades, a unidade social apresenta-se como a segurança de todos, e as consequências dessa sublimação dos instintos recai sobre os ombros dos indivíduos.

Percebe-se que, na denominada sociedade de consumidores, sob o domínio do fetichismo da subjetividade, o preço é a perda do sentido ${ }^{5}$, o que significa entrar em uma sombra que impede a todos de ter a real clareza das coisas e dos seus próprios atos. O universo a que se chega é sem dúvida o da indiferença, da apatia, do não reconhecimento do outro. E Bauman viu nisso tudo um sujeito "desenredado", uma perda de vínculos com tudo e após uma pequena adaptação conceitual deu um nome a tudo isso: melancolia. Diz ele; “ser 'melancólico' é 'sentir a infinidade da conexão, mas não estar engajado em coisa alguma'. Em suma, 'melancolia' se refere a 'uma forma sem conteúdo, uma recusa a saber só isso ou só aquilo" (BAUMAN, 2008, p. 58) (grifo do autor).

A "melancolia" (e Bauman a coloca sempre entre aspas) nesse contexto representa a aflição genérica do consumidor, seria assim, "um distúrbio resultante do encontro fatal entre a obrigação e a compulsão de escolher, o vício da escolha e a incapacidade de fazer essa opção” (BAUMAN, 2008, p. 58). Pode-se concluir que a 'melancolia' é provocada a aparecer num âmbito onde as coisas flutuam sem rumo, aparecendo e desaparecendo segundo os estímulos, marcados pela "indisponibilidade de critérios fidedignos capazes de separar o relevante do irrelevante e a mensagem do ruído” (BAUMAN, 2008, p. 59).

Não é difícil imaginar que o alento oferecido pela sociedade de consumidores esteja na inversão de perspectiva, na história da civilização, este é o único momento em que a felicidade oferecida está na vida terrena. Ergue-se assim uma sociedade de consumidores em massa, voltada para uma satisfação aqui e agora num mundo onde tudo é efêmero, em que os desejos estão continuamente insatisfeitos, onde a lealdade, a confiança e a segurança estão solapadas, e as fontes do medo tornam-se exposta e, assim a vida na modernidade líquida passa a ser determinada pela infelicidade e pelo sofrimento.

\section{CONSIDERAÇÕES FINAIS}

O quadro traçado neste texto, com base em autores já bem conhecidos, buscou tão somente, por meio de uma série de reflexões, percorrer um caminho que leve ao encontro dos desdobramentos sociais e culturais da modernidade. É importante se dar conta que a humanidade vive em um mundo em que pairam ameaças advinda de quase todos os cantos. Aqui quase não se tocou nos efeitos da técnica sobre homem, mas aponta-se para um aprofundamento do grau de alienação provocado por um sistema de produção e consumo que empurram os limites da modernidade, aliás essa seria uma boa pergunta: quais são os limites da modernidade?

$\mathrm{Na}$ sociedade da informação, do mundo digital, qual será a experiência da humanidade com a alienação? A partir das análises do modo de produção capitalista levadas a efeito por Marx vê-se, por meio do fetichismo da mercadoria, elas se posicionarem no lugar do sujeito. Com Bauman detecta-se a definitiva

\footnotetext{
${ }^{5}$ A perda do sentido, a rigor, não é tema tão recente da modernidade. Jean-Paul Sartre a tratou em sua literatura, pode-se encontrar na obra A Náusea (2005) e, também em Albert Camus, principalmente em suas obras, O Homem Revoltado (1999) e O Estrangeiro (2001). Uma boa análise desse tema também pode ser encontrada em Brüseke (1996).
} 
transformação do homem em mercadoria e o domínio do fetichismo da subjetividade. Hoje, depois desse grandioso desenvolvimento da sociedade da informação, que comprimiu ainda mais a relação espaço-tempo, estabelecendo definitivamente a sociedade global, não se estaria diante de um já bem fortalecido fetichismo digital? Talvez seja por esse caminho que se poderia ampliar os horizontes do entendimento dos sentidos ou do aprofundamento da perda destes na sociedade contemporânea.

\section{REFERÊNCIAS}

ADORNO, Theodor \& HORKHEIMER, Max. Dialética do esclarecimento. Rio de Janeiro: Jorge Zahar, 1985.

BAUDRILLARD, Jean. A sociedade de consumo. São Paulo: Elfos, 1995.

BAUMAN, Zygmunt. Comunidade: a busca por segurança no mundo atual. Rio de Janeiro: Zahar, 2003. 2008. Zygmunt. Vida para consumo: a transformação das pessoas em mercadoria. Rio de Janeiro: Zahar,

Modernidade líquida. Tradução Plínio Dentzien. Rio de Janeiro: Jorge Zahar Ed, 2001.

Amor líquido: sobre a fragilidade dos laços humanos. Rio de Janeiro: Zorge Zahar Ed, 2004.

Medo líquido. Rio de Janeiro: Jorge Zahar Ed, 2008.

Vida líquida. Rio de Janeiro: Zahar Editores, 2007a.

Tempos líquidos. Rio de Janeiro: Jorge Zahar Ed, 2007b.

BRITO, Daniel Chaves de \& BARP, Wilson José. Ambivalência e medo: faces dos riscos na modernidade. Sociologias, v. 10, n. 20, 2008.

BRÜSEKE, Franz Josef. A lógica da decadência: desestruturação sócio-econômica, o problema da anomia e o desenvolvimento sustentável. Belém: Editora Cejup, 1996.

BYUNG Chul Han. Sociedade do Cansaço. Petrópolis, RJ: Vozes, 2015.

CAMUS, Albert. Homem revoltado. Rio de Janeiro: Record, 1999. , Albert. O estrangeiro. São Paulo: Editora Record, 2001.

CASTELLS, Manuel. A Sociedade em rede. São Paulo: Paz e Terra, 2000.

DEBORD, Guy. A sociedade do espetáculo. Contraponto: São Paulo, 2016.

ELIAS, Norbert. O processo civilizador, 2Ed, Rio Janeiro: Zahar, 1993.

FREUD, Sigmund. O mal-estar na civilização. São Paulo: Editora Companhia das Letras, 2010.

GIDDENS, Anthony. As consequências da modernidade. 2 ed. São Paulo: Editora Unesp, 1991.

GREHS BECK, Ceres; HERMÍNIO CUNHA, Luis Henrique. As múltiplas faces da comodificação e a constituição da crítica acerca das práticas de consumo contemporâneas. Ciências Sociais Unisinos, v. 53, n. 1, 2017.

KANT, Immanuel et al. O que é esclarecimento. Vozes, p. 100-117, 1985.

LIPOVETSKY, Gilles. A Sociedade da Decepção. Barueri-SP: editora Manole, 2007.

MARX, Karl. O Capital: Crítica da Economia Política. 12 ed. Vol I. Rio de Janeiro: editora Bertrand, 1988.

MARX, Karl \& ENGELS, Friedrich. Manifesto do Partido comunista (1848). Porto Alegre: LP\&M, 2001

SARTRE, Jean-Paul. A Náusea. 12 ed. Rio de Janeiro: Editora Nova Fronteira 2005.

VIRILIO, Paul. Velocidade e Política. São Paulo: Estação da Liberdade, 1996.

WEBER, Max. Economia e Sociedade: Fundamentos da Sociologia Compreensiva. Brasília: Editora universidade de Brasília, 1991. 